\title{
Analysis of Waiting Time for Filing Prescriptions in Hospital Pharmacy
}

\author{
Ulfa Fauzia $^{1}$, Elsa P Setiawati², Emma S Surahman ${ }^{3}$ \\ ${ }^{1}$ Indramayu General Hospital, Indramayu, West Java, Indonesia \\ ${ }^{2}$ Faculty of Medicine, Universitas Padjadjaran, Jatinangor, West Java, Indonesia \\ ${ }^{3}$ Faculty of Pharmacy, Universitas Padjadjaran, Jatinangor, West Java, Indonesia
}

\begin{abstract}
Patient waiting time for healthcare services is identified by the World Health Organization (WHO) as one of the key measurements of a responsive health system. Waiting time for filing prescription can influence patient satisfaction on hospital pharmacy service. This study was conducted to analyze current condition of waiting time for filing precription and related parameters. This study was prospective cross-sectional study conducted for 10 days at a hospital pharmacy, in Indramayu, Indonesia. Data regarding distribution of patients flow was obtained. Statistical analysis was performed using Kolmogorov-Smirnov. We observed that this hospital uses single queue channel-single phase model in three counters, i.e., public health insurance (PHI), private/general, government insurance (GI). The rate of patients visit was $(\lambda) 9.40$ and the rate of service was $(\mu) 1.26$ in PHI. In private/general counter, the rate of patients visit was $(\lambda) 5.03$ and the rate of service was $(\mu) 4.08$. The rate of patients visit was $(\lambda) 4.85$ and the rate of service was $(\mu) 5.85$ in GI. Data indicated that there was excessive work loads. Thus, several strategies should be performed to decrease waiting time, e.g., the use of computer-based queuing system and the improvement of quality and quantity of human resources in the hospital pharmacy.
\end{abstract}

Keywords: waiting time, outpatient, queueing theory.

\section{Introduction}

Patient waiting time for healthcare services is identified by the World Health Organization (WHO) as one of the key measurements of a responsive health system. ${ }^{1}$ Timely services are important in pharmaceutical care to ensure that patients consumed the drugs in appropriate time. Waiting time for filing the

prescription is one of the factor that can influence patient satisfaction on hospital pharmacy service. Patients may easily get tired and impatient when queuing too long for drugs before leaving hospital. ${ }^{1-3}$

The Institute of Medicine (IOM) states there

Corresponding author: Ulfa Fauzia. Indramayu General Hospital, Indramayu, West Java, Indonesia. . Email: ulfa.fauzia@ gmail.com

Received: 3 September 2017. Revised: 7 November 2017. Published: 1 December 2017 
are six goals to be achieved in order to develop quality health services. These six goals are safe, effective, patient-centered, timely, efficient, and equitable. Long duration of prescription service waiting times could be harmful to both health care providers and patients. $^{4}$

Service delays may result in delayed delivery of drugs to the patient. Timely services are also useful to comply Minimum Hospital Service Standards on standard drug service waiting times. Decree of the Minister of Health of the Republic of Indonesia No. 129/ Menkes / SK / III / 2008 on Minimum Hospital Service Standards set the standard waiting time for non-compounding prescription is no more than 30 minutes, and the waiting time for compounding prescription is no more than 60 minutes.

Therefore, this study was conducted to analyze current condition of waiting time for filing precription and related parameters in a hospital pharmacy at Indramayu, Indonesia.
The results of this study can be used to develop strategies to reduce waiting time are expected to be followed up in order to increase the waiting time for prescription services.

\section{Methods}

This cross-sectional study was conducted at a hospital pharmacy in Indramayu, Indonesia. Distribution of patients flow in the counter for public health insurance (PHI), private/ general, and government insurance (GI) counters were obtained.

From each sample, the following information was obtained, i.e, the rate of incoming prescriptions, prescription type, and waiting time included the prescriptions during 08.00 am - $02.00 \mathrm{pm}$ during 10 days. Prescriptions was divided into two types 1) non-compounding 2) compounding. The exclusion criteria were an unreadable recipe sheet, an incomplete recipe sheet, and a recipe sheet that was changed by prescribers after confirmation. Service time includes

Table 1. Patients flow in PHI counter

\begin{tabular}{lcccccc}
\hline \multirow{2}{*}{ Variable } & Poisson & \multicolumn{3}{c}{ Extreme value } & Kol- & \\
\cline { 3 - 6 } & Parameter & Absolute & Positive & Negative & $\begin{array}{c}\text { Aogorov- } \\
\text { Smirnov Z }\end{array}$ & P-value \\
\hline Arrival rate & 14.17 & 0.487 & 0.487 & -0.33 & 1.193 & 0.116 \\
Leaving rate & 14.17 & 0.373 & 0.333 & -0.373 & 0.914 & 0.374 \\
\hline
\end{tabular}

Table 2. Patients flow in general counter

\begin{tabular}{lcccccc}
\hline \multirow{2}{*}{ Variable } & Poisson & \multicolumn{3}{c}{ Extreme value } & Kol- & \\
\cline { 3 - 6 } & Parameter & Absolute & Positive & Negative & $\begin{array}{c}\text { mogorov- } \\
\text { Smirnov Z }\end{array}$ & P-value \\
\hline Arrival rate & 5.5 & 0.412 & 0.412 & -0.309 & 1.008 & 0.261 \\
Leaving rate & 5.5 & 0.412 & 0.412 & -0.228 & 1.008 & 0.261 \\
\hline
\end{tabular}


Table 3. Patients flow in GI counters

\begin{tabular}{|c|c|c|c|c|c|c|}
\hline \multirow[b]{2}{*}{ Variable } & \multirow{2}{*}{$\begin{array}{l}\text { Poisson } \\
\text { Parameter }\end{array}$} & \multicolumn{3}{|c|}{ Extreme value } & \multirow{2}{*}{$\begin{array}{c}\text { Kol- } \\
\text { mogorov- } \\
\text { Smirnov Z }\end{array}$} & \multirow[b]{2}{*}{ P-value } \\
\hline & & Absolute & Positive & Negative & & \\
\hline Arrival Rate & 6.33 & 0.332 & 0.332 & -0.305 & 0.812 & 0.525 \\
\hline Leaving Rate & 6.33 & 0.332 & 0.332 & -0.197 & 0.812 & 0.525 \\
\hline
\end{tabular}

the period starting from the submission the prescription by the patients until the patient was called to receive medication. Service was conducted in accordance with the hospital pharmacy service flow.

To identify the nature of the patient's arrival distribution and patient departure, Kolmogorov-Smirnov's distribution match was performed at 5\% $(\alpha=5 \%)$. Queue parameter was calculated using queuing model $(\mathrm{M} / \mathrm{M} / \mathrm{c}):(\mathrm{GD} / \infty / \infty){ }^{5} \quad$ Statistical analysis was performed using KolmogorovSmirnov.

\section{Results and Discussion}

We observed that this hospital uses single queue channel-single phase model in three counters, i.e., public health insurance (PHI), private/general, government insurance (GI). The rate of patients visit was $(\lambda) 9.40$ and the rate of service was $(\mu) 1.26$ in PHI. In private/general counter, the rate of patients visit was $(\lambda) 5.03$ and the rate of service was $(\mu)$ 4.08. The rate of patients visit was $(\lambda) 4.85$ and the rate of service was $(\mu) 5.85$ in GI.

Table 1, 2, and 3 shows the queue parameter calculation in PHI, general, and GI, respectively. In two former counters, the rate of patients visit compared to service rate was greater than one, indicating there was overload work in both counters. The complete queue parameters could not be calculated for these counters. In the GI counter, the number of queue in average was $4.85 \sim 5$ people and waiting time was approximately 1-0.83 hours. The work utility of the counter was $83 \%$ with $17 \%$ disrupt probability. Although there was no work overload, the waiting time was considerably long. Determination of queuing structure is needed to understand the current condition of queuing system. In two counters, the rate of patients visit excedeed the rate of service, explaining the reason of long queue in these counters.

The patient's satisfaction with the outpatient hospital pharmacy is influenced by the dispensing process, consultation service by pharmacist, and general satisfaction aspect. The dispensing processes includes the waiting time for filling prescription. Making the prescription fillinf efficient and timely is an effective method to improve service quality and improve customer satisfaction. ${ }^{6}$

In developed countries, this can be solved by making arrangement for health service, including consultation with physicians and filling the prescriptions. Therefore, there would be no accumulation of patient visits in certain hours. However it requires established system and commitment from many stakeholders. ${ }^{6,7}$

There are several factors which caused the long waiting time, including lengthy dispensing procedures and lack of human resources both in quantity and quality due to excessive work hours. Re-orientation of the employess could be useful to increase the work performance of the employee. The addition of employee also could increase 
service rate and increase patient satisfaction. ${ }^{7}$

When service demand exceeds the service capacity, instead of queuing up, the patient might choose to leave The phenomenon is called service reneging. Reneging can be prevented by redesigning the queuing system, e.g., by increasing the number of counters. The addition of counters proved to reduce patient waiting time and total costs incurred due to waiting time. ${ }^{89}$ Besides, computerbased queuing system will improve the efficiency, particularly during registration. In addition, patients can see their respective queue numbers, so they can estimate the queue waiting time and thus reduce the accumulation of patients in the waiting room.

The redesign of pharmacy outpatient installations also influences the waiting time of prescription service and patient satisfaction. ${ }^{10}$ When the pharmacists are placed in a location outside the dispensing area, they can communicate with each patient before drugs dispensing process started. ${ }^{9}$ Discipline in the service should also be implemented. Patients who come first are patients who are served first, unless for patients who have more serious medical conditions ${ }^{10,11}$

Further research should be conducted to design the better service system and calculate optimal addition of human resources which might potentially affect the the number of queues and the waiting time of the prescription service. Conversely, the long queue may result in loss of the number of customers and customers satisfaction. Besides, it is also necessary to analyze cost-effectiveness of development of such service system to ensure sustainability of health care service.

\section{Conclusion}

Outpatient prescribing service in this setting used a single-channel, single-phase queuing syetem model, with the average duration of prescription service is 0.83-1 hours. Several strategies should be performed to decrease waiting time, e.g., the use of computer-based queuing system and the imporvement of the quality and quantity of human resources in the hospital pharmacy,

\section{Acknowledgement}

None.

\section{Funding}

None.

\section{Conflict of Interest}

None declared

\section{References}

1. Marquez-Peiro JF, Perez-Peiro C. Evaluation of patient satisfaction in outpatient pharmacy. Hospital Pharmacy. 2008;32(2):71-76.

2. Basu S, Andrews J, Kishore S, Panjabi $\mathrm{R}$, Stuckler D. Comparative performance of private and public healthcare systems. PLoS Medicine. 2012;9(6):e1001244.

3. Rattanachopthanit $\mathrm{T}$, Limwattananon C, Johns R. Assessing the eficiency of hospital pharmacy services in Thai public distric hospital. Southeast Asian Journal of Tropical Medicine and Public Health. 2008;39(4):753-756.

4. Chou Y, Chen BY, Tang YY, Qiu ZI, $\mathrm{Wu} \mathrm{MF}$. Prescription-filling process reengineering of an outpatient pharmacy. Journal of Medicine System. 2012;36 (2): 893-902.

5. Slowiak JM, Huitema BE, Dickinson AM. Reducing wait time in a hospital pharmacy to promote customer service. Quality in Management of Health Care. 2008;17 (2): 112-127.

6. Ameh N, Sabo B, Oyefabi MO. 
Application of queuing theory to patient satisfaction at a tertiary hospital in Nigeria. Nigerian Medical Journal. 2013;54(1): 64-67.

7. Widayanti MW, Mahawati E. Queuing analysis at Wilasa hospital. Medical Journal. 2012;7(2)93-101.

8. Suryadhi RP, Manurung J. Queuing model for hospital health care service. Electrical Engineering Journal. 2009;8(2):16-17.

9. Ndukwe HC, Omale S, Opanuga OO. Reducing queues in a Nigerian hospital pharmacy, African Journal Of Pharmacy and Pharmacology. 2013;5(8):10202026.wan, M. 2005.

10. Bahadori M, Mohammadnejhad SM, Ravangard R, Teymourzadeh E. Using queuing theory and simulation model to optimize hospital pharmacy performance. Iranian Red Crescent Medical Journal. 2014;16(3):e16807.

11. Aeenparast A, Farzadi F, Maftoon F. Waiting time for specialist consultation in Tehran. Archives of Iran Medicines. 2012;15(12):756-758. 